\title{
Análise Morfométrica da Bacia Hidrográfica do Riacho Jucurutu
}

\author{
Morphometric Analysis of the Jucurutu River Watershed
}

FRANCO ${ }^{1}$, V. V.; SOUZA $^{2}$, J. O. P. de.

vifrancol@outlook.com ${ }^{1}$;jonasgeoufpe@yahoo.com.br ${ }^{2}$

\begin{abstract}
Resumo
Este presente trabalho tem como objetivo fazer a caracterização morfométrica da Bacia Hidrográfica do Riacho Jucurutu, localizada no município de São João do Tigre-PB, a partir de alguns parâmetros físicos da mesma. As informações foram geradas a partir do MDE (Modelo Digital de Elevação) ASTER GDEM de 30 metros, onde foram processadas no software ARCGIS 10.2.2. Foi essencial a produção de mapas de declividade e altitude, para uma melhor representação da área. As variáveis definidas de acordo com a morfometria da bacia, como Coeficiente de Compacidade $(2,19)$ e Índice de Circularidade $(0,20)$ permitiram concluir que a bacia possui uma forma alongada tendo uma baixa propensão a enchentes, influenciando assim a dinâmica hidrológica.
\end{abstract}

Palavras-chave: Morfometria; Bacia Hidrográfica; MDE

\begin{abstract}
This present work has as objective making a morphometrical characterization of the Hydrographycal Basin of Jucurutu River, localized in the city of São João do Tigre-PB, from some of its physical parameters. The informations were generated from DEM (Digital Elevation Model) ASTER GDEM of 30 meters, where they were processed in the software ARCGIS 10.2.2. The production of declivity and elevation maps was essential for a better representation of the area. The definited variables according to the morphometry of the basin, as Compactness Coefficient $(2,19)$ and Circularity Index $(0,20)$ allowed concluding that the basin has a elongated shape having a low propensity to flooding, so influencing the hydrological dynamic.
\end{abstract}

Keywords: morphometry; hydrographic basin; MDE.

\section{INTRODUÇÃO}

A bacia hidrográfica ou bacia de drenagem, definida por Christofoletti (1980), é composta por um conjunto de canais de escoamento inter-relacionados, estabelecida como a área drenada por um determinado rio ou rede de drenagem, cujo volume de água nos canais depende de diversos fatores como tamanho da área ocupada pela bacia, da precipitação total e de seu regime, e das perdas devido à evapotranspiração e à infiltração.

Os estudos sobre a Geomorfologia fluvial são fundamentais tanto para o entendimento da evolução das paisagens geográficas e modificações de sua dinâmica fluvial, quanto para determinar o domínio sobre os processos de erosão e sedimentação resultantes de meios naturais ou da ação antrópica sobre a área de estudo. Como o estudo da declividade/gradiente que possibilita entender a energia de transporte, velocidade do fluxo de água, profundidade do canal e, consequentemente compreender a dinâmica do ambiente fluvial (RODRIGUES, CASTRO E MALAFAIA 2010).

A análise morfométrica é uma ferramenta fundamental para a análise da dinâmica e da sensibilidade da bacia à deterioração ambiental. Sendo assim, os parâmetros morfométricos são obtidos a partir

\footnotetext{
${ }^{1}$ Virna Vieira Franco, Departamento de Geociências/Laboratório Oficina de Geografia da Paraíba - LOGEPA, Universidade Federal da Paraíba, João Pessoa-PB,Brasil

${ }^{2}$ Jonas Otaviano Praça de Souza, Departamento de Geociências/Laboratório Oficina de Geografia da Paraíba - LOGEPA, Universidade Federal da Paraíba, PB, Brasil
} 
dos dados físicos de uma bacia, possuindo uma forte conexão com a morfologia, o clima e a pedoforma. Além disso, os parâmetros morfométricos exibem determinadas classes de informações e diferenças essenciais entre as distintas paisagens da bacia, fornecendo dados com relação ao número de canais e sua ordem, assim como a área, extensão, perímetro e dados altimétricos (FEITOSA, SANTOS E ARAUJO 2011). Em síntese, a análise morfométrica é de grande relevância para os estudos geomorfológicos, possibilitando a obtenção de informações sobre a dinâmica da paisagem.

Com o advento do geoprocessamento e dos dados topográficos digitais, os Modelos Digitais de Elevação - MDE, em especial os gerados a partir dos dados SRTM (Shuttle Radar Topographic Mission), TOPODATA e ASTER (Advanced Spaceborne Thermal Emission and Reflection Radiometer), têm ganhado relevância por decorrerem de técnicas rápidas e precisas para a coleta de dados topográficos. Sendo disponibilizados gratuitamente na Internet, permitindo a elaboração de mapeamentos de áreas, delineamento de redes de drenagem, disponibilização de dados altimétricos do relevo, delimitação de bacias hidrográficas e imagens de alta resolução através do sensoriamento remoto, bem como a facilidade de analisar, comparar e atualizar informações da superfície terrestre (OLIVEIRA et al 2010).

Desse modo, este presente artigo visa analisar a fisiografia Bacia Hidrográfica do Riacho Jucurutu (BHRJ), localizada no município de São João do Tigre-PB, a partir de estudos relacionados aos parâmetros morfométricos, para uma melhor compreensão dos aspectos físicos e do comportamento da bacia em estudo. Vale ressaltar que a BHRJ está posta em um ambiente semiárido, apresentando apenas riachos intermitentes e efêmeros.

\section{METODOLOGIA}

A área em estudo (Bacia Hidrográfica do Riacho Jucurutu - BHRJ) encontra-se inserida na microrregião do Cariri Ocidental, semiárido paraibano, fazendo fronteira com o Pernambuco na porção sul do estado da Paraíba, estando inserida quase completamente no município de São João do Tigre, cuja área é de $816,116 \mathrm{~km}^{2}$ (IBGE, 2010) e possuindo o bioma caatinga. Além disso, a bacia está inserida na unidade do Planalto da Borborema em um setor de Depressão Intraplanáltica Paraibana, o qual possui um clima semiárido severo reinante, não permite o desenvolvimento de regolito e detém feições bastante planas, limitadas ao sul pelo setor dos Maciços Remobilizados do Domínio da Zona Transversal, o qual apresenta uma sucessão de maciços isolados, cristais e depressões intraplanálticas estreitas, como por exemplo o Maciço da Serra Negra de Bezerros e o Batólito de Brejo da Madre de Deus (CORRÊA et al 2010). Está localizada em uma área de relevo 
suave ondulado e ondulado em sua maioria, na porção Norte. Já na porção Sul, a declividade é caracterizada por fortes ondulações e áreas dissecadas de declividade alta, áreas elevadas com topo plano (ROMANO 2016).

Inicialmente foi feita a delimitação da bacia do Riacho Jucurutu e gerada sua drenagem de forma automatizada, entretanto, para serem obtidos resultados mais precisos, a drenagem foi corrigida manualmente a partir de imagens disponibilizadas no Google Earth, e de dados de campo obtidos por GPS sendo utilizados como pontos de controle para a correção do posicionamento dos canais. Nesse momento foi possível, entre outras correções, a exclusão de canais inexistentes que são geradas pelo método automático de extração de drenagem. Após a correção, a drenagem foi exportada para o formato compatível com o ARCGIS 10.2.2, para que fosse possível processamento das informações (SOUZA E ALMEIDA 2014). Para o presente trabalho foi utilizado o MDE (Modelo Digital de Elevação) gerado a partir de dados ASTER GDEM de 30 metros, o qual cobre 99\% da superfície da Terra. Diferentemente do SRTM (Shuttle Radar Topography Mission) que obtém os resultados através de radar, o ASTER GDEM produz imagens óticas através de infravermelhos, podendo ter interferências de nuvens ou de efeitos da atmosfera (FERRAZ 2014). Os resultados obtidos no ASTER GDEM foram processados possibilitando o cálculo das características morfométricas da bacia.

Desta forma, as variáveis definidas para o presente trabalho foram: Com relação à morfometria da bacia - área da bacia $\left(\mathrm{km}^{2}\right)$; coeficiente de compacidade $\left(\mathrm{m} / \mathrm{m}^{2}\right)$; altitude máxima, média e mínima; amplitude; índice de circularidade $\left(\mathrm{m}^{2} / \mathrm{m}\right)$; densidade de drenagem $\left(\mathrm{km} / \mathrm{km}^{2}\right)$; índice de bifurcação; número de canais por ordem; número total de canais e a densidade dos canais.

O coeficiente de compacidade é a relação entre o perímetro da bacia e a circunferência de um círculo de área igual à da bacia (VILLELA E MATTOS 1975). De forma geral, o coeficiente de compacidade indica qual a tendência que a bacia possui para a ocorrência de enchentes, onde quanto mais irregular for a bacia, tanto maior será o coeficiente de compacidade. Quanto a densidade de drenagem, ainda de acordo com Villela \& Mattos (1975), é a relação entre os comprimentos total dos cursos d'água de uma bacia e sua área total. A densidade de drenagem é considerada por muitos um dos mais importantes parâmetros morfométricos, sendo utilizada em diversas aplicações para o conhecimento e interpretação do comportamento do meio físico, resultado de inter-relações de fatores condicionantes, como clima, especialmente pluviometria, substrato geológico, solos, relevo, etc., permitindo, portanto, que sejam correlacionados entre si (SANTOS et al 2005). De acordo com os critérios de Villela \& Mattos (1975), o índice da 
densidade de drenagem varia de $0,5 \mathrm{~km} / \mathrm{km}^{2}$, para bacias com drenagem pobre, a $3,5 \mathrm{~km} / \mathrm{km}^{2}$ ou mais, para bacias significativamente bem drenadas.

O índice de bifurcação é a relação de um canal de certa ordem e o número de ordem do canal superior. O índice de circularidade, indicando o quão a bacia se aproxima da forma circular. $\mathrm{O}$ critério utilizado para o índice de circularidade foi proposto por Christofoletti (1980) definindo, portanto, o quão alongada é a bacia, pois o valor máximo a ser atingido é 1,0, e quanto maior for o valor, mais próxima da forma circular se encontra a bacia. E a amplitude altimétrica da bacia, sendo o resultado da diferença entre altitude máxima e a altitude mínima.

Já com relação à morfometria de encosta, a variável definida foi a declividade máxima, média e mínima, apresentada em porcentagem para exibir o nível de declive do relevo da bacia, sendo que para cada $100 \mathrm{~m}$ horizontalmente a declividade varia $100 \mathrm{~m}$ verticalmente, cujas classes definidas para o mapa seguem orientação do Manual Técnico de Pedologia da Embrapa (2009); e, finalmente, com relação à morfometria hidráulica: o gradiente do canal principal, onde foi feita a diferença entre a altitude máxima e a altitude mínima do canal principal (em metros) e o comprimento do canal (em quilômetros); e perfil longitudinal, possibilitando a observação de perfil do nível de declínio da bacia.

\section{RESULTADOS E DISCUSSÃO}

A análise a partir dos parâmetros morfométricos (tabela 01) possibilitou um estudo mais claro com relação ao relevo da bacia hidrográfica do Riacho Jucurutu, a qual está inserida no município de São João do Tigre-PB, possuindo uma área de 564,899 km² (Figura 1), obtendo canal de $5^{\text {a }}$ ordem.

Tabela 1: Índices morfométricos da Bacia do Riacho Jucurutu

\begin{tabular}{|c|c|}
\hline Características Morfométricas & Valores \\
\hline Área da bacia & $564,899 \mathrm{~km}^{2}$ \\
\hline Coeficiente de Compacidade & 2,19 \\
\hline Altitude Máxima & $1172 \mathrm{~m}$ \\
\hline Altitude Média & $838 \mathrm{~m}$ \\
\hline Altitude Mínima & $506 \mathrm{~m}$ \\
\hline Amplitude & $666 \mathrm{~m}$ \\
\hline
\end{tabular}




\begin{tabular}{|c|c|} 
Índice de Circularidade & 0,2 \\
\hline Densidade de Drenagem & 0,69 \\
\hline Índice de Bifurcação & 3,6 \\
\hline Número total de canais & 158 \\
\hline Densidade dos Canais & 0,28 por km² \\
\hline Declividade Máxima & $114 \%$ \\
\hline Declividade Média & $10 \%$ \\
\hline Gradiente do canal principal & $7,6 \mathrm{~m} / \mathrm{Km}$ \\
\hline
\end{tabular}

\section{Mapa de Localização da Bacia Hidrográfica do Riacho Jucurutu}
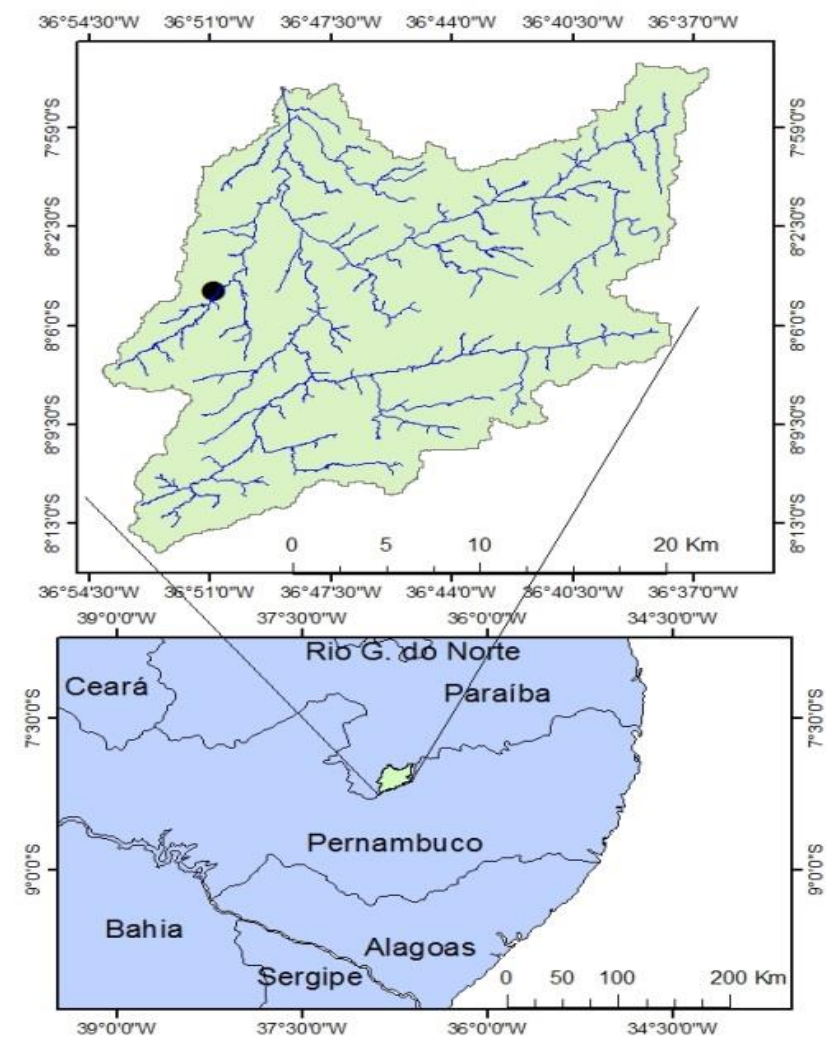

Legenda

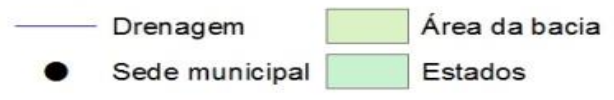

Sistemas de Coordenadas Geográficas Datum: SIRGAS 2000

- Sede municipal Estados

Figura 1: Mapa de Localização da Bacia Hidrográfica do Riacho Jucurutu.

A altitude máxima da bacia do Riacho Jucurutu é de 1172 metros e a altitude mínima é de 506 metros. A partir disso, foi possível calcular a amplitude, que foi medida pela diferença entre os valores da altitude máxima e a altitude mínima, obtendo uma amplitude de 666 metros, juntamente com a altitude média igual a 838 metros e o desvio padrão com o valor de 191,99 metros, pode-se 
inferir que comparando com outras áreas semiáridas a bacia do Riacho Jucurutu possui uma alta variação de altitude, como é possível observar na Figura 2. É possível verificar que na região sudoeste e sudeste a bacia detém as maiores altitudes, por estar presente sua área de cabeceiras, além estar inserida no setor de Maciços Remobilizados do Domínio da Zona Transversal, apresentando cimeiras mais elevadas e relevos mais vigorosos, além de exibir a presença de intrusões brasilianas de variadas dimensões. Todavia, essa altitude vai diminuindo na mesma proporção em que o rio segue seu médio e baixo curso, passando a fazer parte do setor de Depressão Intraplanáltica Paraibana, apresentando formas bastante planas em seu relevo (CORRÊA et al, 2010).

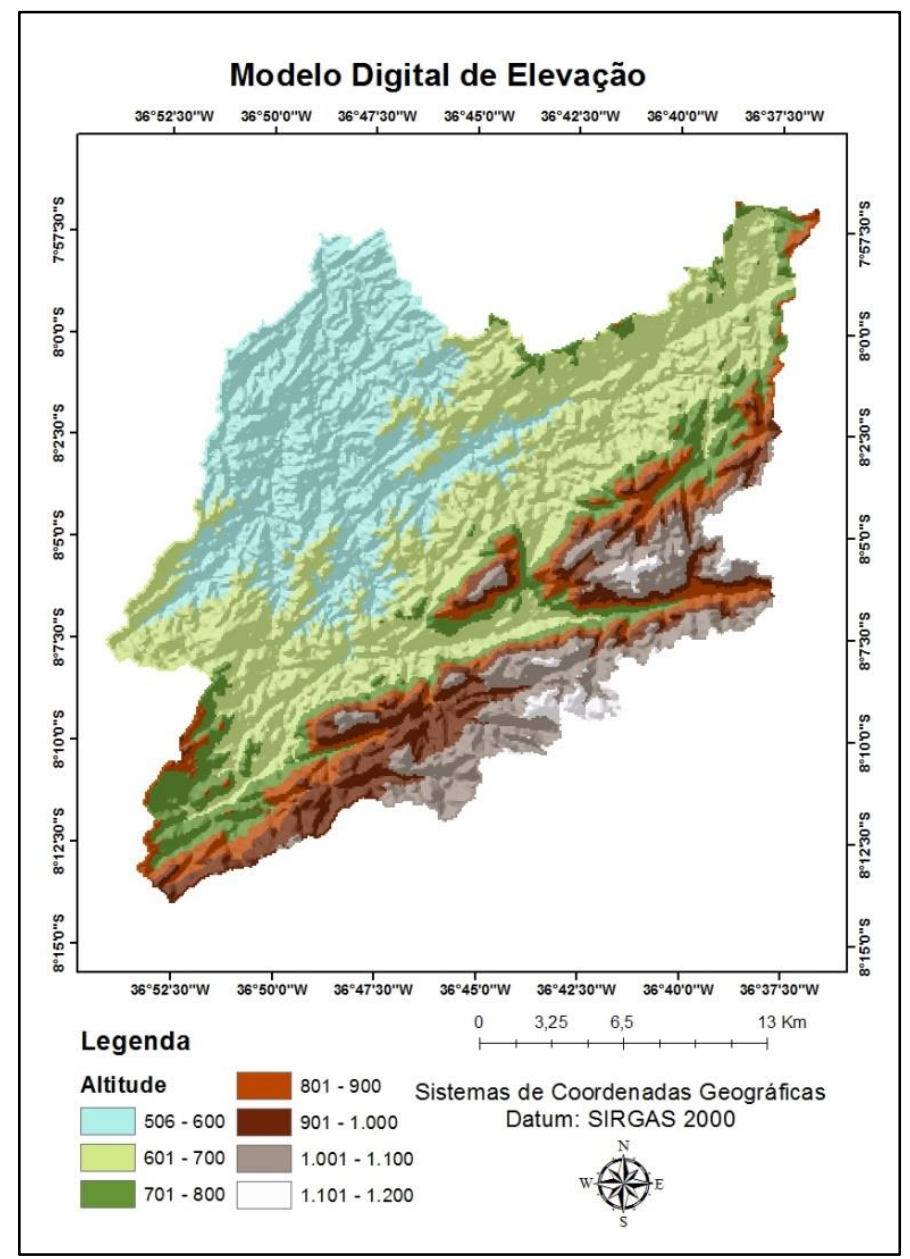

Figura 2: Mapa hipsométrico.

Foi confeccionado o mapa de declividade da área para demonstrar o grau de inclinação do relevo, a qual possui uma declividade máxima de $114 \%$, declividade média de $10 \%$ e o desvio padrão de 10,99\%, influenciando os processos erosivos, a densidade de drenagem, velocidade de escoamento, entre outros diversos fatores, a partir do controle da energia da encosta que, consequentemente, aumenta a velocidade de fluxo e a sua capacidade erosiva. As classes definidas 
para o mapa seguem orientação do Manual Técnico de Pedologia da Embrapa (Figura 3). Assim como no mapa de altitude, na região sudoeste e especialmente na região sudeste, a bacia apresenta um índice de declividade mais elevado expondo índices montanhosos, por exemplo. Entretanto, na porção norte a bacia expõe uma declividade suave ondulado, em sua maioria. Logo, de forma geral, a bacia possui predominantemente um relevo suave ondulado e ondulado.

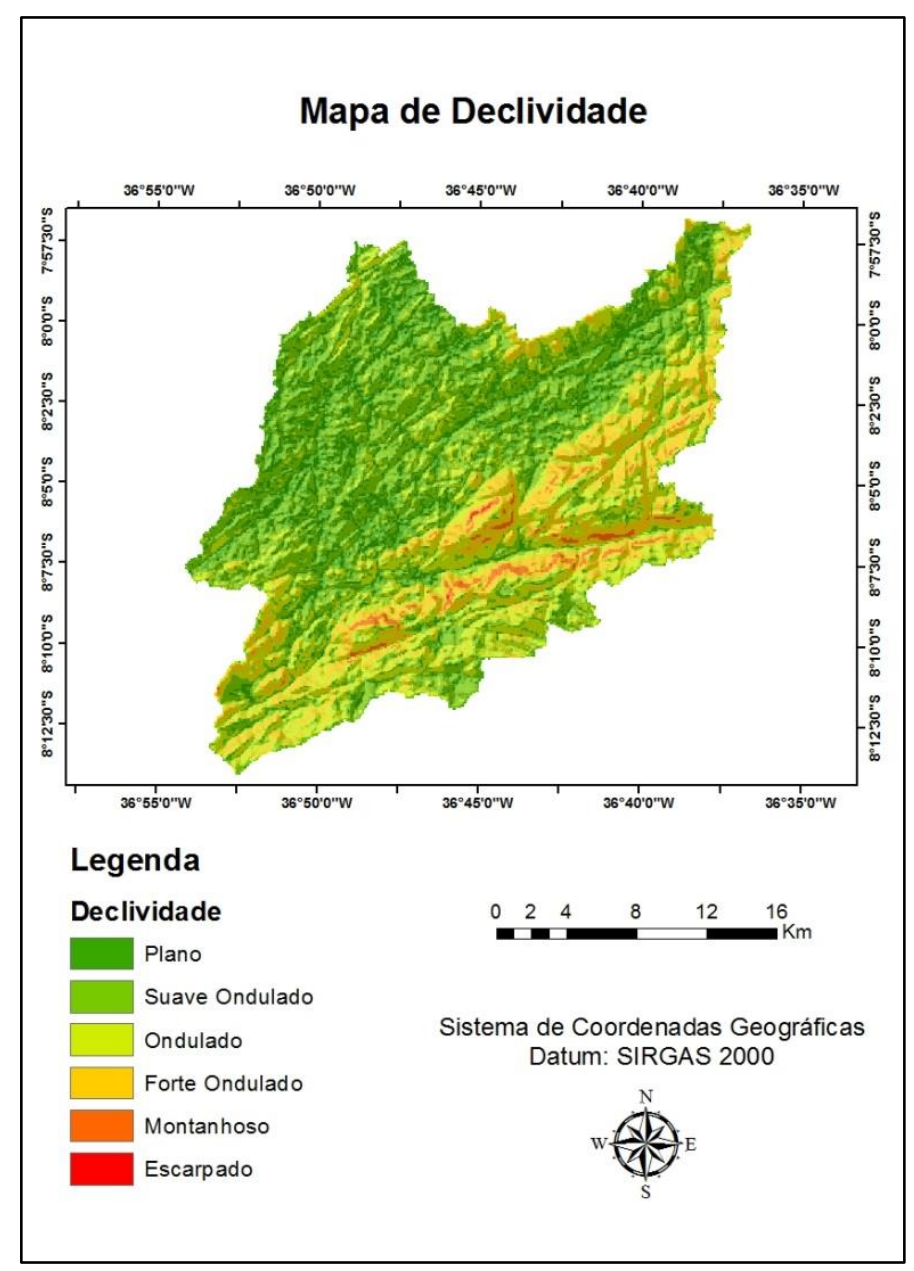

Figura 3: Mapa de Declividade

Em relação à morfometria da bacia, a análise do coeficiente de compacidade da bacia obteve um valor de 2,19. Deste modo, o coeficiente encontrado para a bacia indica baixa probabilidade de ocorrer grandes enchentes. Outra variável que designa a forma da bacia é o índice de circularidade, cujo valor encontrado foi de 0,20 , apontando que a bacia em estudo apresenta circularidade. A bacia do Riacho Jucurutu detém 158 canais, a qual dispõe de 155 canais de primeira ordem, 51 canais de segunda ordem, 9 canais de terceira ordem, 3 canais de quarta ordem, e 1 canal de quinta ordem. A partir das ordens dos canais foi calculado o índice de bifurcação, sendo de 3,6, indicando um grau intermediário de dissecação do relevo. 
Desse modo, as variáveis: coeficiente de compacidade, índice de bifurcação, e índice de circularidade indicaram que a bacia apresenta uma forma alongada, possuindo a dissecação do relevo média, a maior parte da área apresenta dissecação de cerca de $30 \mathrm{~m}$, contudo em áreas isoladas de escarpa e vales encaixados ao sul chega a 300 metros; e uma baixa propensão a enchentes, possuindo também efeitos sobre a dinâmica hidrológica da bacia.

Por fim, a análise morfométrica linear, relativa à rede de drenagem em si (CHRISTOFOLETTI 1980), define o comprimento total dos canais $390 \mathrm{~km}$ (quilômetros). Relacionando com a área da bacia foi calculado uma densidade de drenagem baixa com o valor de $0,69 \mathrm{~km} / \mathrm{km}^{2}$. Associando as informações lineares com a área da bacia, a densidade dos canais foi calculada a partir da relação do número total de canais com a área da bacia que resultou uma densidade de 0,28 por $\mathrm{km}^{2}$. Sendo assim, um dos fatores da densidade da bacia não ser tão elevada se dá pelo fato de que a mesma encontra-se em uma região semiárida, logo, por estar inserida em uma área que contém baixa pluviosidade e um clima quente e seco, dentre outros fatores como solo e relevo, por exemplo, influenciam a formação de linhas de drenagem.

A partir do perfil longitudinal do canal principal (Figura 4) observa-se que o canal apresenta anomalias em sua forma ao ser comparado a ideia de rios em equilíbrio, assim as quebras nos valores de gradiente do canal geram diversas áreas com a possibilidade de aumento significativo de velocidade e energia da vazão nos trechos de aumento de declive, como no trecho por volta de 4 quilômetros de distância da cabeceira. As anormalidades existentes no rio podem estar relacionadas a controles estruturais como a presença de falhas ou variações litológicas. O gradiente para todo o canal principal foi medido a partir da diferença altimétrica máxima e mínima do canal principal em metros e o comprimento do canal em quilômetros, que foi igual a 7,6 m/Km.

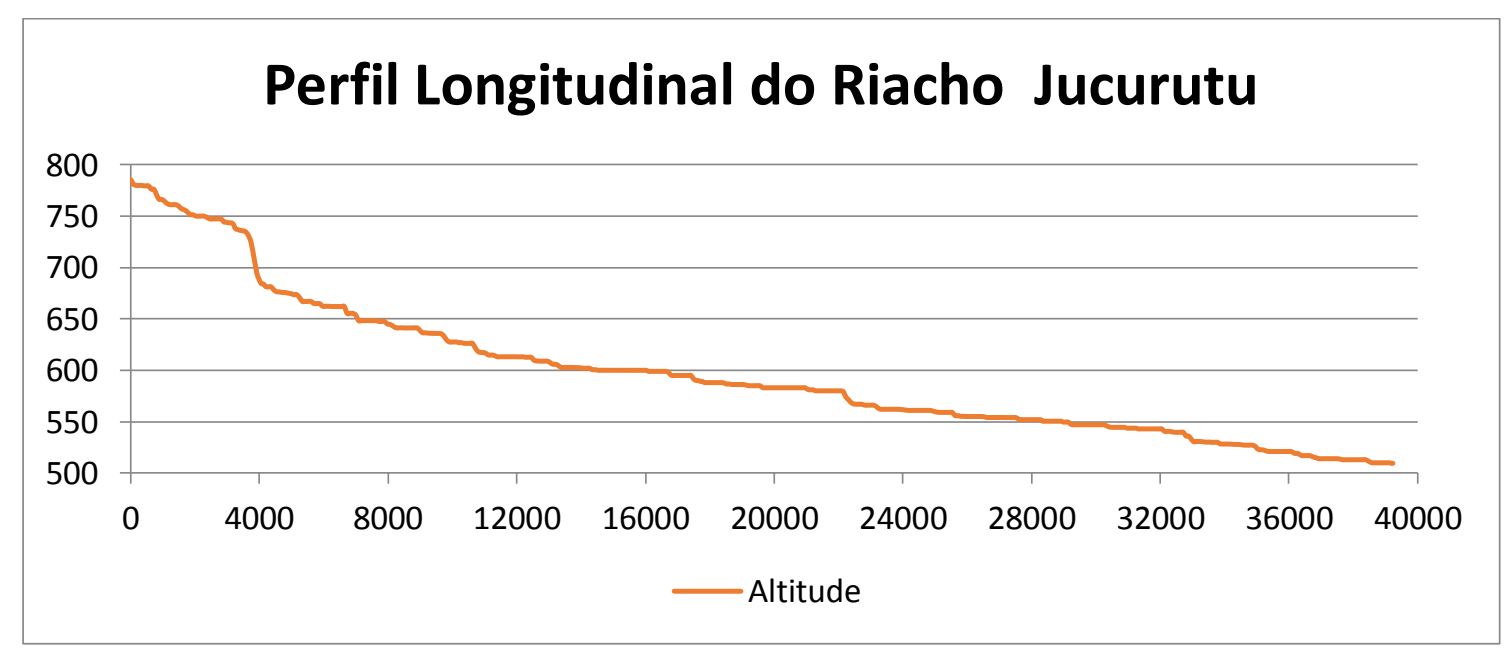

Figura 4: Perfil longitudinal da bacia do Riacho Jucurutu em metros. 
Desse modo, de acordo com os resultados obtidos a partir da análise das características morfométricas da bacia do Riacho Jucurutu, a mesma possui pouca susceptibilidade a enchentes, apresentando forma alongada, sendo confirmado pelo Coeficiente de Compacidade $(2,19)$ e Índice de Circularidade (0,20). Além disso, apresenta variações no índice de dissecação, onde a presença de atividades erosivas é mais intensa em áreas mais dissecadas (ROMANO 2016). A bacia ainda possui uma densidade considerada intermediária, porém detém uma distribuição irregular, apresentando áreas com muitos canais e áreas com poucos canais. As áreas com maior dissecação e de maior densidade de drenagem coincidem com as áreas com alta declividade e maior altitude no sul e sudoeste da bacia.

\section{CONSIDERAÇÕES FINAIS}

Foi fundamental o uso da análise dos dados morfométricos como primeiro diagnóstico sobre a bacia, cujos resultados permitiram informações sobre sua dinâmica e drenagem, podendo contribuir com próximos estudos na área de Bacias Hidrográficas localizadas no semiárido devido à carência de pesquisas realizadas em tais áreas, levando em consideração que a bacia possui cursos d'água intermitentes.

Desta forma, pode-se constatar pelos resultados que a água permanece pouco tempo na bacia, ou seja, é removida rapidamente, como pode ser observado pelos índices de circularidade $(0,20)$, de bifurcação $(3,6)$ e de compacidade $(2,19)$. Tais índices em conjunto com altos valores de gradiente, como pode ser observado na imagem gerada do perfil longitudinal (Figura 4), indicam que durante os eventos onde há fluxos na bacia a água é drenada rapidamente apesar dos valores baixos de densidade de drenagem e de canais. Desse modo, mesmo no baixo curso, onde canal apresenta os menores valores de gradiente, não há recorrência de enchentes, nem de formação de áreas predominantemente alagadas, ou até largas planícies de inundação.

\section{REFERÊNCIAS}

CARELLI, L; LOPES, P. P. Caracterização Fisiográfica da Bacia Olhos D’água em Feira de Santana/BA: Geoprocessamento Aplicado à Análise Ambiental. Boletim Goiano de Geografia 2011, v. 31. Goiânia, GO.

CHRISTOFOLETTI, A. Geomorfologia 2 ${ }^{\mathrm{a}}$ Ed., São Paulo, SP. Editora Blucher, 1980.

CORREAA, A. C. B; TAVARES, B. A. C; MONTEIRO, K. A; CAVAlCANTI, L. C. S; LIRA, D. R. Megageomorfologia e Morfoestrutura do Planalto da Borborema. Revista do Instituto Geológico. São Paulo, 2010. 
FEITOSA, A; SANTOS, B; ARAÚJO, M. S. B. Caracterização Morfométrica e identificação de Áreas Susceptíveis a Erosão na Bacia do Rio Pajeú, PE: o Estudo de Caso da Bacia do Rio Pajeú/PE. Revista Brasileira de Geografia Física. 2011. v. 04.

FERRAZ, R.S. Avaliação de Modelos Digitais de Terreno para Delimitação de Áreas de Bacias Hidrográficas. V Simpósio Brasileiro de Ciências Geodésicas e Tecnologias da Geoinformação. Recife, PE. 2014.

OLIVEIRA, P. T. S.; ALVES SOBRINHO, T.; STEFFEN, J. L.; RODRIGUES, D. B. B. Caracterização morfométrica de bacias hidrográficas através de dados SRTM. Revista Brasileira de Engenharia Agrícola e Ambiental, 2010. v. 14, n. 8, p. Campina Grande.

RODRIGUES, A. S. L; CASTRO, P. T. A; MALAFAIA, G. Utilização dos Protocolos de Avaliação Rápida de Rios como Instrumentos Complementares na Gestão de Bacias Hidrográficas Envolvendo Aspectos da Geomorfologia Fluvial: Uma Breve Discussão. Enciclopédia Biosfera vol. 6. Goiânia, GO. Centro Científico Conhecer, 2010.

ROMANO, M.P.C.G; Análise da fragilidade ambiental, na bacia do Riacho Jucurutu/Raposa em São João do Tigre-PB. Monografia de Graduação apresentada na UFPB. 2016. 70p.

SANTOS, A. M. S; ALVES, C. F. C; GAMA, R. G; FERRACINI, M. M; PERRELLA, M. C. V; CARVALHO, N. O; CELER, A. Densidade de Drenagem da Bacia Incremental do Reservatório de Porto Primavera, rio Paraná (SP/MS): perspectiva de sua adoção como indicador de produção de sedimentos das bacias hidrográficas. Revista Brasileira de Geomorfologia. 2005. Ano 6. n 1.

SOUZA, J. O. P; ALMEIDA, J. D. M. Modelo Digital de Elevação e Extração Automática de Drenagem: Dados, Métodos e Precisão para Estudos Hidrológicos e Geomorfológicos. Boletim de Geografia. 2014. v. 32. n 2. Maringá.

VILLELA S. M; MATTOS, A. Hidrologia Aplicada. Editora McGraw-Hill do Brasil, Ltda. São Paulo, SP. 1975.

Recebido em: 14/08/2016

Aceito para publicação em: 01/10/2016 